
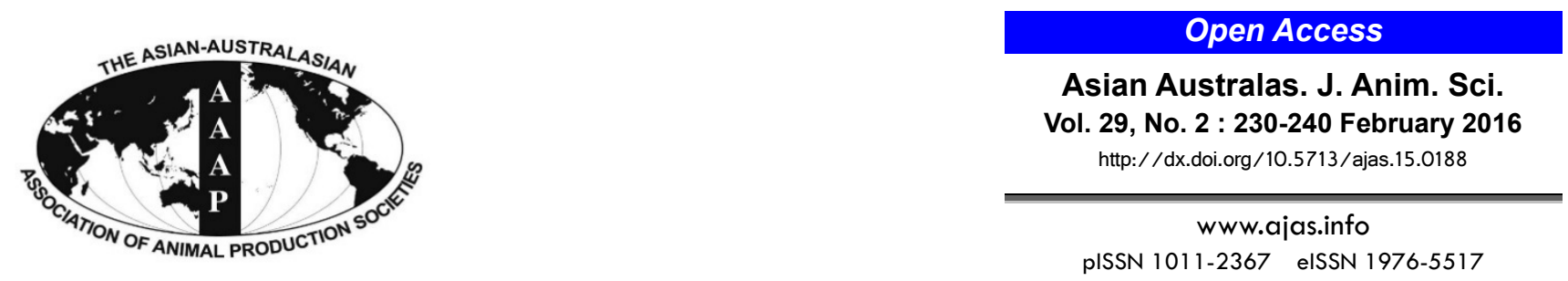

\title{
Evaluation of Different Yeast Species for Improving In vitro Fermentation of Cereal Straws
}

\author{
Zuo Wang ${ }^{1,2}$, Zhixiong $\mathrm{He}^{2}$, Karen A. Beauchemin ${ }^{2}$, Shaoxun Tang, Chuanshe Zhou*, \\ Xuefeng Han, Min Wang, Jinhe Kang, Nicholas E. Odongo ${ }^{3}$, and Zhiliang Tan \\ Key Laboratory for Agro-Ecological Processes in Subtropical Region, \\ Hunan Research Center of Livestock and Poultry Sciences, \\ South-Central Experimental Station of Animal Nutrition and Feed Science in Ministry of Agriculture, \\ Institute of Subtropical Agriculture, The Chinese Academy of Sciences, Changsha 410125, China
}

\begin{abstract}
Information on the effects of different yeast species on ruminal fermentation is limited. This experiment was conducted in a $3 \times 4$ factorial arrangement to explore and compare the effects of addition of three different live yeast species (Candida utilis 1314, Saccharomyces cerevisiae 1355 , and Candida tropicalis 1254$)$ at four doses $\left(0,0.25 \times 10^{7}, 0.50 \times 10^{7}\right.$, and $0.75 \times 10^{7}$ colony-forming unit [cfu]) on in vitro gas production kinetics, fiber degradation, methane production and ruminal fermentation characteristics of maize stover, and rice straw by mixed rumen microorganisms in dairy cows. The maximum gas production ( $V f)$, dry matter disappearance (IVDMD), neutral detergent fiber disappearance (IVNDFD), and methane production in $C$. utilis group were less $(p<0.01)$ than other two live yeast supplemented groups. The inclusion of $S$. cerevisiae reduced $(\mathrm{p}<0.01)$ the concentrations of ammonia nitrogen $\left(\mathrm{NH}_{3}-\mathrm{N}\right)$, isobutyrate, and isovalerate compared to the other two yeast groups. C. tropicalis addition generally enhanced (p<0.05) IVDMD and IVNDFD. The $\mathrm{NH}_{3}-\mathrm{N}$ concentration and $\mathrm{CH}_{4}$ production were increased $(\mathrm{p}<0.05)$ by the addition of $S$. cerevisiae and $C$. tropicalis compared with the control. Supplementation of three yeast species decreased $(p<0.05)$ or numerically decreased the ratio of acetate to propionate. The current results indicate that $C$. tropicalis is more preferred as yeast culture supplements, and its optimal dose should be $0.25 \times 10^{7} \mathrm{cfu} / 500 \mathrm{mg}$ substrates in vitro. (Key Words: Fiber Degradation, In vitro Fermentation, Live Yeast, Methane, Volatile Fatty Acids)
\end{abstract}

\section{INTRODUCTION}

Supplementation with yeast products in the diets has become a common practice in improving the efficiency of feed utilization and the performance of ruminants for over

\footnotetext{
* Corresponding Author: Chuanshe Zhou. Tel: +86-73184619702, Fax: +86-731-84612685, E-mail: zcs@isa.ac.cn

${ }^{1}$ University of the Chinese Academy of Sciences, Beijing 100049, China.

${ }^{2}$ Lethbridge Research Centre, Agriculture and Agri-Food Canada, Lethbridge T1J 4B1, Canada.

3 Animal Production and Health Section, Joint FAO/IAEA Division of Nuclear Techniques in Food and Agriculture, International Atomic Energy Agency, Vienna A-1400, Austria. Submitted Mar. 4, 2015; Revised May 1, 2015; Accepted May 19, 2015
}

20 years (Moallem et al., 2009). It has been confirmed that yeast culture supplementation benefits digestion and metabolism of ruminants in several aspects, such as the improvement of nutrient digestibility, optimization of the proportion of volatile fatty acids (VFA) in the rumen, decrease in the ruminal ammonia nitrogen $\left(\mathrm{NH}_{3}-\mathrm{N}\right)$, alleviation of $\mathrm{pH}$ fluctuation, and stimulation of ruminal microorganism population (Chaucheyras-Durand et al., 2008). Furthermore, it has been verified that yeast culture inclusion in the diets of ruminants can provide various growth factors, pro-vitamins and other stimulants to rumen microorganisms, and balance the ruminal fluid redox potential to create the optimal fermentation conditions for the rumen bacterial microflora (Jouany, 2001).

In the past few years, it had also been demonstrated that 
dietary live yeast supplementation plays a beneficial role in the improvement of ruminant's productivity. Holtshausen and Beauchemin (2010) reported that live yeast (Levucell SC1077) supplementation had a positive effect on milk yield and milk efficiency in cows fed a barley-based diet. In another study, dietary live yeast supplementation in dairy cows during the hot season in Israel improved the rumen environment by enhancing the ruminal $\mathrm{pH}$ and ammonia utilization, and in consequence improved dry matter (DM) intake, productivity and conversion efficiency of feeds (Moallem et al., 2009).

However, as observed in many studies so far, the effectiveness of dietary yeast products inclusion are variable, which might be ascribed to variation between animals, experimental diets fed, method of feeding, strains of yeasts, and their viability as well. For instance, supplementing beef cattle with Saccharomyces cerevisiae could raise the live weight by $7.5 \%$ depending on the type of diet tested, while improvement reached 13\% in feedlot for diets rich in starch and sugars (Estefan, 1999). Supplementation of yeast culture improved the rate of gas production (GP), DM and organic matter disappearances for rice straw, wheat straw and maize stover (Tang et al., 2008). Meanwhile, dietary inclusion of $S$. cerevisiae NCYC 240, NCYC 1026 and Yea-Sacc stimulated total and cellulolytic bacterial numbers, while S. cerevisiae NCYC 694 and NCYC 1088 exerted no influence on the numbers of bacteria in vitro (Newbold et al., 1995).

Up to now, there is still little available information about the variation in the ruminal fermentation resulting from the addition of different live yeast species. Hence, the objectives of this study were to explore and compare the effects of three different species of yeasts (Candida utilis 1314, S. cerevisiae 1355, and Candida tropicalis 1254) on the in vitro ruminal fermentation characteristics of rice straw and maize stover by ruminal microorganisms from dairy cows, to further understand the mode of action of live yeast species in the rumen, and to provide more valuable information on the live yeast application to ruminants' diets in practice.

\section{MATERIALS AND METHODS}

\section{Crop straws, yeasts, and experimental design}

Two types of crop straws which are most commonly used as roughage in diets for dairy cows in south China, i.e., maize stover (Zea mays, variety Kexiang Sweet Corn No. 1, Changsha, China) and rice straw (Oryza sativa, variety Xiang 125S/BAR-1, Changsha, China) were selected as in vitro fermentation substrates in this study. They were dried at $65^{\circ} \mathrm{C}$ for $24 \mathrm{~h}$, and then ground through a $1 \mathrm{~mm}$ sieve and stored in plastic bags for assay. Maize stover and rice straw contained (DM basis): 52.3 and $62.4 \mathrm{~g}$ crude protein
(CP)/kg, 636 and $632 \mathrm{~g}$ neutral detergent fiber (NDF)/kg, and 386 and $434 \mathrm{~g}$ acid detergent fiber (ADF) $/ \mathrm{kg}$, respectively.

Three different species of yeasts (C. utilis 1314, S. cerevisiae 1355 , and C. tropicalis 1254 ) originally used as feed additives, were purchased from and reactivated by the China Center of Industrial Culture Collection. Yeasts were cultured and amplified using liquid malt extract medium (130 g malt extract and $0.1 \mathrm{~g}$ chloramphenicol/L), then their total viable numbers were counted in the form of colonyforming units (cfu) by employing the spread plate method. Afterwards, the yeasts were preserved at $4^{\circ} \mathrm{C}$ until the in vitro fermentation was started. The experiment was conducted in a $3 \times 4$ factorial arrangement, factors included yeast (three yeast species) and dose $\left(0 \times 10^{7} \mathrm{cfu}\right.$ [without addition of yeast], $0.25 \times 10^{7} \mathrm{cfu}, \quad 0.50 \times 10^{7} \mathrm{cfu}$, and $\left.0.75 \times 10^{7} \mathrm{cfu}\right)$.

\section{In vitro gas production and sampling}

Culture solutions, i.e., macroelement solution, buffered solution and reducing solution used for in vitro fermentation were prepared to form artificial saliva according to the procedures modified by Tang et al. (2006). The artificial saliva was kept anaerobic by continuously pumping carbon dioxide for $2 \mathrm{~h}$.

Rumen fluids were obtained from three rumencannulated Holstein dairy cows fed ad libitum a mixed diet of rice straw and concentrate (60:40, weight/weight) offered twice daily at 07:00 and 19:00 h. Concentrate contained (per 1,000 g DM): $396 \mathrm{~g}$ ground maize, $181 \mathrm{~g}$ soybean meal, $10 \mathrm{~g} \mathrm{CaHPO}_{4}, 3 \mathrm{~g}$ limestone meal and $10 \mathrm{~g}$ premix. The rumen-cannulated Holstein dairy cows were managed according to the protocols approved by the Animal Care and Use Guidelines of the Animal Care Committee, Institute of Subtropical Agriculture, The Chinese Academy of Sciences, Changsha, China. Rumen contents of each dairy cow were obtained from various locations within the rumen immediately before the morning feeding, mixed and strained through four layers of cheesecloth under a continuous $\mathrm{CO}_{2}$ stream. The obtained rumen fluids were then anaerobically combined with artificial saliva in the proportion of 1 to 9 at $39^{\circ} \mathrm{C}$.

Samples of strawor stoverin an amount of $500 \pm 10 \mathrm{mg}$ was accurately weighed into $100-\mathrm{mL}$ fermentation bottles (Wanhong Glass Instrument Factory, Haimen, China) prewarmed at $39^{\circ} \mathrm{C}$, then $50 \mathrm{~mL}$ of the mixed fluids (artificial saliva plus rumen fluids) were introduced into each bottle using a dispenser (Varispenser 4960000.060; Eppendorf, Wesseling-Berzdorf, Germany). After that, the yeasts were respectively added according to the abovementioned different doses when the in vitro fermentation was started. Blanks containing only mixed fluids, mixed fluids and substrates, mixed fluids and different doses of 
yeasts were all incubated together with the treated bottles.

All fermentation bottles were connected with pressure sensors (CYG130-12; SQsensor, Kunshan, China) and incubated at $39^{\circ} \mathrm{C}$. The pressure in all the bottles was recorded at $0,1,2,4,6,12,24$, and 48 hours during the process of in vitro fermentation. Each time at 12, 24, and 48 $\mathrm{h}$, three bottles for each treatment were respectively taken out from the incubator to stop the incubation. After termination of incubation, a $5 \mathrm{~mL}$ gas sample was collected into the vacuum flask (LabcoExetainer; Labco, High Wycombe, UK) with plastic syringe for $\mathrm{CH} 4$ determination, and then undegraded residues were immediately filtered through 2 layers of nylon cloth (40-um pore size). The incubation solutions of each treatment were sampled for determination of $\mathrm{NH}_{3}-\mathrm{N}$ and VFA concentrations at 12, 24, and $48 \mathrm{~h}$, respectively. In vitro fermentation was separately run three times on different days to result in nine analytical replicates (i.e., three analytical replicates per run).

\section{Chemical analysis}

The DM (method 930.15) and CP $(6.25 \times \mathrm{N}$, method 990.03) were analyzed using the procedures of the Association of Official Analytical Chemists (AOAC, 1999). The NDF and ADF content were determined using a Fibretherm Fiber Analyzer (Gerhardt, Bonn, Germany) according to Van Soest et al. (1991) with addition of sodium sulphite and alpha-amylase in the NDF analysis. The filtered residues were dried at $105^{\circ} \mathrm{C}$ for $12 \mathrm{~h}$ and weighed for in vitro dry matter disappearance (IVDMD) determination. The NDF content in the dried residues was determined to calculate in vitro NDF disappearance (IVNDFD).

Two $\mathrm{mL}$ of incubation solution was centrifuged at $10,000 \times \mathrm{g}$ at $4^{\circ} \mathrm{C}$ for $15 \mathrm{~min}$, then $1.5 \mathrm{~mL}$ of supernatant solution was taken and $0.15 \mathrm{~mL}$ of metaphosphoric acid was added and homogenized. The mixed solution was centrifuged at $10,000 \times \mathrm{g}$ at $4^{\circ} \mathrm{C}$ for $15 \mathrm{~min}$ again, and the supernatant solution was used to determine VFA content with a gas chromatograph (HP5890, Agilent 5890; Agilent Technologies, Palo Alto, CA, USA). A DB-FFAP column (30 $\mathrm{m}$ in length with a $0.25 \mathrm{~mm}$ inside diameter [i.d.]) was used for the separation. The attenuation was set at a nitrogen diffluent ratio of 1:50, hydrogen flow $30 \mathrm{~mL} / \mathrm{min}$, airflow $365 \mathrm{~mL} / \mathrm{min}$, injector temperature $250^{\circ} \mathrm{C}$, column temperature $150^{\circ} \mathrm{C}$, and detector temperature $220^{\circ} \mathrm{C}$. The $\mathrm{N}_{2}$ was used as carrier gas at a flow rate of $0.8 \mathrm{~mL} / \mathrm{min}$. The relative response factor, representing the peak of each VFA, was calculated using the standard VFA mixture, which was chromatographed with each group of 10 samples. Total molar concentration was calculated by taking the sum of individual VFA as 1.

For the determination of $\mathrm{NH}_{3}-\mathrm{N}, 5 \mathrm{~mL}$ of incubation solution was centrifuged at $4,000 \times \mathrm{g}$ and $4^{\circ} \mathrm{C}$ for $10 \mathrm{~min}$, then $2 \mathrm{~mL}$ of the supernatant solution was taken and mixed with $8 \mathrm{~mL} \quad 0.2 \mathrm{M} \mathrm{HCl}$ into a tube followed by homogenization. Subsequently, $0.4 \mathrm{~mL}$ of the mixed solution was taken and mixed with $2 \mathrm{~mL}$ of sodium nitroprusside solution $(0.08 \mathrm{~g}$ sodium nitroprusside dissolved in $100 \mathrm{~mL}$ of 0.14 natrium salicylicum) and $2 \mathrm{~mL}$ of prepared solution ( $2 \mathrm{~mL}$ sodium hypochlorite solution mixed with $100 \mathrm{~mL} 0.3 \mathrm{M}$ sodium hydroxide solution), then transferred into a tube followed by homogenization and equilibrated at room temperature for $10 \mathrm{~min}$. The light absorption value was recorded at $700 \mathrm{~nm}$ using spectrophotometer (UV-2300; Shimadzu, Kyoto, Japan).

The $\mathrm{CH}_{4}$ analysis was performed by gas chromatography (GC)-flame ionization detection using GC (GC7890A; Agilent Technologies, USA) equipped with a Hayesep Q packing column (2.44 $\mathrm{M} \times 1 / 8$ in. $\times 2.0 \mathrm{~mm}$ i.d.). The temperature of column and injector was respectively set at $60^{\circ} \mathrm{C}$ and $100^{\circ} \mathrm{C}$ for $3 \mathrm{~min}$. The $\mathrm{N}_{2}$ was used as carrier gas at a flow rate of $21 \mathrm{~mL} / \mathrm{min}$.

\section{Calculation and statistical analysis}

During the initial stages of this work, the correlation between the pressure in bottle and gas volume was measured at $39^{\circ} \mathrm{C}$, and the regression equation was then established:

$$
y=1.506 x\left(n=20, r^{2}=0.999, p<0.0001\right)
$$

Where y represents gas volume $(\mathrm{mL}), \mathrm{x}$ is the pressure in bottle $(\mathrm{kPa}), 1.506$ is a constant. The measured pressure was then converted to GP ( $\mathrm{mL})$. In vitro $\mathrm{GP}$ at $0,1,2,4,6$, 12,24 , and 48 hours was fitted to Logistic-Exponential (Wang et al., 2011):

$$
\mathrm{GP}=\mathrm{Vf}(1-\exp (\mathrm{d}-\mathrm{t} \times \mathrm{k})) /(1+\exp (\mathrm{b}-\mathrm{k} \times \mathrm{t}))
$$

Where GP represents GP at $\mathrm{t}$ time, $\mathrm{Vf}$ means the maximum GP $(\mathrm{mL}), \mathrm{k}$ represents GP fraction $(/ \mathrm{h}), \mathrm{b}$ and $\mathrm{d}$ represent the shapes of the GP curve. The time $\left(\mathrm{t}_{0.5}, \mathrm{~h}\right)$ when half of the maximum GP was achieved and the initial fractional rate of degradation $(/ \mathrm{h})$ were calculated by respectively employing the following two equations (Wang et al., 2011; Wang et al., 2013):

$$
\begin{aligned}
& \mathrm{t}_{0.5}=\operatorname{In}(\exp (\mathrm{b})+2 \exp (\mathrm{d})) / \mathrm{k} \\
& \mathrm{FRD}_{0}=\mathrm{k} /(1+\exp (\mathrm{b}))(4)
\end{aligned}
$$

GP, IVDMD, and IVNDFD were corrected by subtracting the values obtained for the blanks. Data were analyzed by two-way analysis of variance in the MIXED procedure of SAS (SAS Institute Inc., Cary, NC, USA) 
(SAS Institute Inc., 2001). For GP parameters, the model included species, dose, and species $\times$ dose as fixed effects. For $\mathrm{pH}, \mathrm{NH}_{3}-\mathrm{N}, \mathrm{CH}_{4}$ production, VFAs, IVDMD and IVNDFD, the fixed effects of species, dose, and species $\times$ dose were included in the model, with incubation time as a repeated effect. The bottle was used as the experimental unit, and run and bottle were considered as random effects in the entire study. Linear and quadratic effects of dose were analyzed using orthogonal polynomial contrasts. Cubic effects of dose were not examined for inexplicability in biology. Least squares means are reported throughout the text, and significance was declared at $\mathrm{p}<0.05$.

\section{RESULTS}

\section{In vitro gas production parameters}

For maize stover, in vitro GP parameters generally were not affected by yeast species except for $V f$, which was respectively $7 \%$ and $8 \%$ higher $(\mathrm{p}<0.01)$ for $S$. cerevisiae and $C$. tropicalis than the $C$. utilis (Table 1). All the parameters, except $F R D_{0}$, were influenced to a certain extent by yeast dose being dependent on yeast species. The C. utilis addition quadratically decreased $(\mathrm{p}<0.05) \mathrm{Vf}$, while linearly reduced $(\mathrm{p}<0.01) k$. The addition of $C$. tropicalis showed a quadratic decreasing $(\mathrm{p}<0.05)$ effect on $t_{0.5}$. In comprehensive consideration of the effectiveness of improving GP and rate, the optimum supplemental dose of $S$. cerevisiae and C. tropicalis would be $0.25 \times 10^{7} \mathrm{cfu}$ and
$0.75 \times 10^{7} \mathrm{cfu}$, respectively.

For rice straw, the yeast species exerted significant effects $(\mathrm{p}<0.01)$ on $V f$ and $F R D_{0}$ (Table 2). Compared with the addition of $C$. utilis, $V f$ for $S$. cerevisiae and $C$. tropicalis were respectively $16 \%$ and $19 \%$ higher. Besides, $F R D_{0}$ was $43 \%$ higher for the $C$. tropicalis treatment than for the $S$. cerevisiae treatment. The dose effects of yeast addition on in vitro GP parameters were dependent on yeast species. The addition of $C$. utilis decreased $k$ and $t_{0.5}$ in the same manner (linear, $\mathrm{p}<0.05$ ), but increased $F R D_{0}$ (linear, $\mathrm{p}<0.05)$. Moreover, a quadratic $(\mathrm{p}<0.05)$ dose response to $S$. cerevisiae addition for $V f$ was positively observed. The profitable effects of $C$. tropicalis addition on $F R D_{0}$ (linear, $\mathrm{p}<0.01$ ) and $t_{0.5}$ (linear, $\mathrm{p}<0.05$ ) were also noted. The interactive effects of species and dose on $V f$ and $t_{0.5}$ were observed $(\mathrm{p}<0.05)$. Generally considering in vitro GP and rate, the optimum supplemental doses of $S$. cerevisiae and $C$. tropicalis might both be $0.25 \times 10^{7} \mathrm{cfu}$.

\section{In vitro dry matter and neutral detergent fiber disappearance}

For maize stover, the yeast species affected IVDMD and IVNDFD $(\mathrm{p}<0.01) \quad($ Table 3$)$. The lowest IVDMD and IVNDFD were observed in the $C$. utilis treatment, the former was $5 \%$ and $13 \%$ less, while the latter was $11 \%$ and $21 \%$ lower, when compared with $S$. cerevisiae and $C$. tropicalis treatment, respectively. A linear decrease $(\mathrm{p}<0.01)$ both in IVDMD and in IVNDFD was noted in response to

Table 1. Effects of different yeast species addition on in vitro gas production kinetics for maize stover

\begin{tabular}{|c|c|c|c|c|c|c|c|c|c|c|}
\hline \multirow{2}{*}{ Item } & \multirow{2}{*}{ Species } & \multicolumn{5}{|c|}{ Dose $\left(\times 10^{7}\right.$ colony-forming unit $)$} & \multirow{2}{*}{$\mathrm{SEM}^{2}$} & \multicolumn{3}{|c|}{ Significance $(>p)^{3}$} \\
\hline & & Mean ${ }^{1}$ & 0 & 0.25 & 0.50 & 0.75 & & Species & Dose & Species $\times$ dose \\
\hline \multirow[t]{4}{*}{$\overline{V f(\mathrm{~mL})}$} & Candida utilis & $67.97^{\mathrm{f}}$ & $71.33^{\mathrm{a}}$ & $65.50^{\mathrm{ab}}$ & $64.25^{\mathrm{b}}$ & $70.80^{\mathrm{a}}$ & 2.013 & $<0.01$ & $\mathrm{Q}(<0.05)$ & NS \\
\hline & Saccharomyces cerevisiae & $72.85^{\mathrm{e}}$ & 71.33 & 75.91 & 72.16 & 71.99 & & & NS & \\
\hline & Candida tropicalis & $73.12^{\mathrm{e}}$ & 71.33 & 72.45 & 72.45 & 76.24 & & & NS & \\
\hline & $\mathrm{SEM}^{4}$ & 1.006 & & & & & & & & \\
\hline \multirow[t]{4}{*}{$k(/ \mathrm{h})$} & Candida utilis & 0.087 & $0.105^{\mathrm{a}}$ & $0.108^{\mathrm{a}}$ & $0.091^{\mathrm{a}}$ & $0.043^{\mathrm{b}}$ & 0.0113 & NS & $\mathrm{L}(<0.01)$ & NS \\
\hline & Saccharomyces cerevisiae & 0.010 & 0.105 & 0.010 & 0.096 & 0.098 & & & NS & \\
\hline & Candida tropicalis & 0.097 & 0.105 & 0.102 & 0.100 & 0.081 & & & NS & \\
\hline & SEM & 0.0056 & & & & & & & & \\
\hline \multirow[t]{4}{*}{$F R D_{0}(/ \mathrm{h})$} & Candida utilis & 0.027 & 0.024 & 0.025 & 0.026 & 0.034 & 0.0038 & NS & NS & NS \\
\hline & Saccharomyces cerevisiae & 0.023 & 0.024 & 0.026 & 0.021 & 0.021 & & & NS & \\
\hline & Candida tropicalis & 0.027 & 0.024 & 0.028 & 0.026 & 0.031 & & & NS & \\
\hline & SEM & 0.0019 & & & & & & & & \\
\hline \multirow[t]{4}{*}{$t_{0.5}(\mathrm{~h})$} & Candida utilis & $17.10^{\mathrm{e}}$ & 16.84 & 15.42 & 16.67 & 19.49 & 0.729 & NS & NS & NS \\
\hline & Saccharomyces cerevisiae & $16.96^{\mathrm{ef}}$ & 16.84 & 15.67 & 17.75 & 17.58 & & & NS & \\
\hline & Candida tropicalis & $15.91^{\mathrm{f}}$ & 16.84 & 15.11 & 15.72 & 15.98 & & & $\mathrm{Q}(<0.05)$ & \\
\hline & SEM & 0.364 & & & & & & & & \\
\hline
\end{tabular}

SEM, standard error of the mean; NS, not significant.

${ }^{1}$ Mean for individual species across doses including the dose of 0 .

${ }^{2}$ SEM for strain $\times$ dose.

${ }^{3} \mathrm{NS}(\mathrm{p}>0.05), \mathrm{L}=$ linear effect of dose, $\mathrm{Q}=$ quadratic effect of dose.

${ }^{4}$ SEM for pooled mean of species including the dose of 0 .

${ }^{a, b}$ Means within a row for doses that do not have a common superscript differ $(p<0.05)$.

${ }^{e, f}$ Means within a column for species that do not have a common superscript differ $(\mathrm{p}<0.05)$. 
Table 2. Effects of different yeast species addition on in vitro gas production kinetics for rice straw

\begin{tabular}{|c|c|c|c|c|c|c|c|c|c|c|}
\hline \multirow{2}{*}{ Item } & \multirow{2}{*}{ Species } & \multicolumn{5}{|c|}{ Dose $\left(\times 10^{7}\right.$ colony-forming unit) } & \multirow{2}{*}{$\mathrm{SEM}^{2}$} & \multicolumn{3}{|c|}{ Significance $(>p)^{3}$} \\
\hline & & Mean $^{1}$ & 0 & 0.25 & 0.50 & 0.75 & & Species & Dose & Species $\times$ dose \\
\hline \multirow[t]{4}{*}{$V f(\mathrm{~mL})$} & Candida utilis & $53.23^{\mathrm{f}}$ & 58.46 & 53.12 & 50.31 & 51.05 & 2.564 & $<0.01$ & NS & $<0.05$ \\
\hline & Saccharomyces cerevisiae & $61.68^{\mathrm{e}}$ & $58.46^{\mathrm{b}}$ & $69.13^{\mathrm{a}}$ & $60.30^{\mathrm{b}}$ & $58.82^{\mathrm{b}}$ & & & $\mathrm{Q}(<0.05)$ & \\
\hline & Candida tropicalis & $63.55^{\mathrm{e}}$ & 58.46 & 67.48 & 62.86 & 65.41 & & & NS & \\
\hline & $\mathrm{SEM}^{4}$ & 1.282 & & & & & & & & \\
\hline \multirow[t]{4}{*}{$k(/ \mathrm{h})$} & Candida utilis & $0.101^{\text {ef }}$ & $0.119^{\mathrm{a}}$ & $0.110^{\mathrm{ab}}$ & $0.100^{\mathrm{ab}}$ & $0.074^{\mathrm{b}}$ & 0.0122 & NS & $\mathrm{L}(<0.05)$ & NS \\
\hline & Saccharomyces cerevisiae & $0.115^{\mathrm{e}}$ & 0.119 & 0.103 & 0.121 & 0.117 & & & NS & \\
\hline & Candida tropicalis & $0.093^{\mathrm{f}}$ & 0.119 & 0.078 & 0.099 & 0.077 & & & NS & \\
\hline & SEM & 0.0061 & & & & & & & & \\
\hline \multirow[t]{4}{*}{$F R D_{0}(/ \mathrm{h})$} & Candida utilis & $0.018^{\mathrm{ef}}$ & $0.013^{b}$ & $0.014^{\mathrm{b}}$ & $0.020^{\mathrm{ab}}$ & $0.024^{\mathrm{a}}$ & 0.0023 & $<0.01$ & $\mathrm{~L}(<0.05)$ & NS \\
\hline & Saccharomyces cerevisiae & $0.014^{\mathrm{f}}$ & 0.013 & 0.016 & 0.014 & 0.013 & & & NS & \\
\hline & Candida tropicalis & $0.020^{\mathrm{e}}$ & $0.013^{b}$ & $0.021^{\mathrm{a}}$ & $0.021^{\mathrm{a}}$ & $0.025^{\mathrm{a}}$ & & & $\mathrm{L}(<0.01)$ & \\
\hline & SEM & 0.0011 & & & & & & & & \\
\hline \multirow[t]{4}{*}{$t_{0.5}(\mathrm{~h})$} & Candida utilis & 19.31 & $19.98^{\mathrm{a}}$ & $19.67^{\mathrm{a}}$ & $18.25^{\mathrm{b}}$ & $19.34^{\mathrm{ab}}$ & 0.412 & NS & $\mathrm{L}(<0.05)$ & $<0.05$ \\
\hline & Saccharomyces cerevisiae & 19.36 & 19.98 & 19.20 & 18.65 & 19.63 & & & NS & \\
\hline & Candida tropicalis & 19.07 & $19.98^{\mathrm{a}}$ & $20.07^{\mathrm{a}}$ & $17.97^{\mathrm{b}}$ & $18.26^{\mathrm{b}}$ & & & $\mathrm{L}(<0.05)$ & \\
\hline & SEM & 0.206 & & & & & & & & \\
\hline
\end{tabular}

SEM, standard error of the mean; NS, not significant.

${ }^{1}$ Mean for individual species across doses including the dose of 0 .

${ }^{2}$ SEM for strain $\times$ dose.

${ }^{3} \mathrm{NS}(\mathrm{p}>0.05), \mathrm{L}=$ linear effect of dose, $\mathrm{Q}=$ quadratic effect of dose.

${ }^{4}$ SEM for pooled mean of species including the dose of 0 .

${ }^{\mathrm{a}, \mathrm{b}}$ Means within a row for doses that do not have a common superscript differ $(\mathrm{p}<0.05)$.

${ }^{\mathrm{e}, \mathrm{f}}$ Means within a column for species that do not have a common superscript differ $(\mathrm{p}<0.05)$.

the increase of $C$. utilis addition, while the $C$. tropicalis addition linearly increased IVDMD and IVNDFD $(p<0.05)$, and the maximum IVDMD and IVNDFD were both achieved at the supplemental dose of $0.75 \times 10^{7} \mathrm{cfu}$, which were respectively $12 \%$ and $22 \%$ greater than the control.

As for rice straw, IVDMD and IVNDFD were influenced $(p<0.01)$ by the yeast species, and the least IVDMD and IVNDFD were observed in the $C$. utilis treatment, the former was $7 \%$ and $13 \%$ less, while the latter was $15 \%$ and $20 \%$ less than those of $S$. cerevisiae and $C$. tropicalis treatment, respectively. The $C$. utilis supplementation decreased IVDMD (linear, $\mathrm{p}<0.01$ ) and IVNDFD (quadratic, $p<0.01)$. A quadratic $(p<0.01)$ response in IVNDFD to $C$. tropicalis addition was noted, and the greatest IVNDFD occurred at the supplemental dose of $0.25 \times 10^{7} \mathrm{cfu}$, which was improved by $16 \%$ compared with the control.

\section{pH, $\mathrm{NH}_{3}-\mathrm{N}$ and $\mathrm{CH}_{4}$ production}

For maize stover, yeast species affected $(p<0.01)$ the $\mathrm{NH}_{3}-\mathrm{N}$ concentration of in vitro fermentation liquors and $\mathrm{CH}_{4}$ production/g IVDMD (Table 4). The $\mathrm{NH}_{3}-\mathrm{N}$ concentration of the $S$. cerevisiae treatment was respectively $6 \%$ and $8 \%$ less than those of the C. utilis and C. tropicalis treatments, while the $\mathrm{CH}_{4}$ production for $C$. utilis addition was respectively $12 \%$ and $10 \%$ lower than the addition of $S$. cerevisiae and $C$. tropicalis. A linear reduction $(\mathrm{p}<0.05)$ in $\mathrm{pH}$ value was noted for both the $C$. utilis and $C$. tropicalis treatments, while a quadratic response and a linear increase in the concentration of $\mathrm{NH}_{3}$ $\mathrm{N}$ were observed for the $S$. cerevisiae $(\mathrm{p}<0.05)$ and $C$. tropicalis $(\mathrm{p}<0.01)$ treatments, respectively. Besides, the addition of $S$. cerevisiae and $C$. tropicalis caused overall increases in $\mathrm{CH}_{4}$ production, which were quadratic $(\mathrm{p}<0.01)$ and linear $(\mathrm{p}<0.01)$, respectively. Moreover, the greatest $\mathrm{CH}_{4}$ production in those two yeast treatments were both achieved at the supplemental dose of $0.50 \times 10^{7} \mathrm{cfu}$, which were respectively $33 \%$ and $26 \%$ greater than the control. There was an interactive effect $(p<0.05)$ of species and dose on the $\mathrm{NH}_{3}-\mathrm{N}$ concentration.

As regards rice straw, the yeast species influenced the $\mathrm{NH}_{3}-\mathrm{N}$ concentration of fermentation liquors $(\mathrm{p}<0.01)$ and $\mathrm{CH}_{4}$ production/g IVDMD $(\mathrm{p}<0.01)$. The $\mathrm{NH}_{3}-\mathrm{N}$ concentration in the $S$. cerevisiae treatment was respectively $7 \%$ and $18 \%$ lower than those of C. utilis and C. tropicalis treatment, while $\mathrm{CH}_{4}$ production supplemented with $C$. utilis was $8 \%$ less than that of $S$. cerevisiae, and $10 \%$ less than that of $C$. tropicalis. The $\mathrm{pH}$ value decreased in response to the addition of $C$. utilis (linear, $\mathrm{p}<0.01$ ), $S$. cerevisiae (quadratic, $\mathrm{p}<0.05$ ), and $C$. tropicalis (quadratic, $\mathrm{p}<0.01$ ). As for the concentration of $\mathrm{NH}_{3}-\mathrm{N}$, a quadratic reduction and a linear increase $(\mathrm{p}<0.01)$ were observed with the increasing doses of $S$. cerevisiae and $C$. tropicalis, respectively. The $\mathrm{CH}_{4}$ production was increased by the 
Table 3. Effects of different yeast species addition on IVDMD and IVNDFD of maize stover and rice straw

\begin{tabular}{|c|c|c|c|c|c|c|c|c|c|c|}
\hline \multirow{2}{*}{ Item } & \multirow{2}{*}{ Species } & \multicolumn{5}{|c|}{ Dose $\left(\times 10^{7}\right.$ colony-forming unit $)$} & \multirow{2}{*}{$\mathrm{SEM}^{2}$} & \multicolumn{3}{|c|}{ Significance $(>p)^{3}$} \\
\hline & & Mean ${ }^{1}$ & 0 & 0.25 & 0.50 & 0.75 & & Species & Dose & Species $\times$ dose \\
\hline \multicolumn{11}{|l|}{ Maize stover } \\
\hline \multirow[t]{4}{*}{ IVDMD (mg/mg) } & Candida utilis & $0.499^{\mathrm{g}}$ & $0.531^{\mathrm{a}}$ & $0.505^{\mathrm{ab}}$ & $0.483^{\mathrm{b}}$ & $0.478^{\mathrm{b}}$ & 0.0002 & $<0.01$ & $\mathrm{~L}(<0.01)$ & $<0.05$ \\
\hline & $\begin{array}{l}\text { Saccharomyces } \\
\text { cerevisiae }\end{array}$ & $0.526^{\mathrm{f}}$ & 0.531 & 0.529 & 0.497 & 0.548 & & & NS & \\
\hline & Candida tropicalis & $0.574^{\mathrm{e}}$ & $0.531^{\mathrm{b}}$ & $0.589^{\mathrm{a}}$ & $0.580^{\mathrm{a}}$ & $0.597^{\mathrm{a}}$ & & & $\mathrm{L}(<0.05)$ & \\
\hline & SEM $^{4}$ & 0.0001 & & & & & & & & \\
\hline \multirow[t]{4}{*}{ IVNDFD (mg/mg) } & Candida utilis & $0.380^{\mathrm{g}}$ & $0.424^{\mathrm{a}}$ & $0.356^{\mathrm{b}}$ & $0.380^{\mathrm{ab}}$ & $0.359^{\mathrm{b}}$ & 0.0002 & $<0.01$ & $\mathrm{~L}(<0.01)$ & $<0.01$ \\
\hline & $\begin{array}{l}\text { Saccharomyces } \\
\text { cerevisiae }\end{array}$ & $0.428^{\mathrm{f}}$ & 0.424 & 0.431 & 0.426 & 0.430 & & & NS & \\
\hline & Candida tropicalis & $0.484^{\mathrm{e}}$ & $0.424^{b}$ & $0.500^{\mathrm{a}}$ & $0.493^{\mathrm{a}}$ & $0.518^{\mathrm{a}}$ & & & $\mathrm{L}(<0.05)$ & \\
\hline & SEM & 0.0001 & & & & & & & & \\
\hline \multicolumn{11}{|l|}{ Rice straw } \\
\hline \multirow[t]{4}{*}{ IVDMD (mg/mg) } & Candida utilis & $0.442^{\mathrm{g}}$ & $0.482^{\mathrm{a}}$ & $0.453^{\mathrm{ab}}$ & $0.424^{\mathrm{bc}}$ & $0.408^{\mathrm{c}}$ & 0.0001 & $<0.01$ & $\mathrm{~L}(<0.01)$ & $<0.01$ \\
\hline & $\begin{array}{l}\text { Saccharomyces } \\
\text { cerevisiae }\end{array}$ & $0.475^{\mathrm{f}}$ & 0.482 & 0.471 & 0.472 & 0.473 & & & NS & \\
\hline & Candida tropicalis & $0.509^{\mathrm{e}}$ & 0.482 & 0.527 & 0.523 & 0.503 & & & NS & \\
\hline & SEM & 0.0001 & & & & & & & & \\
\hline \multirow[t]{4}{*}{ IVNDFD (mg/mg) } & Candida utilis & $0.339^{\mathrm{f}}$ & $0.402^{\mathrm{a}}$ & $0.347^{b}$ & $0.298^{\mathrm{b}}$ & $0.310^{\mathrm{b}}$ & 0.0002 & $<0.01$ & $\mathrm{Q}(<0.01)$ & $<0.01$ \\
\hline & $\begin{array}{l}\text { Saccharomyces } \\
\text { cerevisiae }\end{array}$ & $0.400^{\mathrm{e}}$ & 0.402 & 0.398 & 0.395 & 0.405 & & & NS & \\
\hline & Candida tropicalis & $0.423^{\mathrm{e}}$ & $0.402^{b}$ & $0.467^{\mathrm{a}}$ & $0.464^{\mathrm{a}}$ & $0.359^{\mathrm{b}}$ & & & $\mathrm{Q}(<0.01)$ & \\
\hline & SEM & 0.0001 & & & & & & & & \\
\hline
\end{tabular}

IVDMD, in vitro dry matter disappearance; IVNDFD, in vitro neutral detergent fiber; SEM, standard error of the mean; NS, not significant.

${ }^{1}$ Mean for individual species across doses including the dose of 0 .

${ }^{2}$ SEM for strain $\times$ dose.

${ }^{3} \mathrm{NS}(\mathrm{p}>0.05) ; \mathrm{L}=$ linear effect of does; $\mathrm{Q}=$ quadratic effect of dose.

${ }^{4} \mathrm{SEM}$ for pooled mean of species including the dose of 0 .

${ }^{\mathrm{a}-\mathrm{c}}$ Means within a row for doses that do not have a common superscript differ $(\mathrm{p}<0.05)$.

${ }^{\mathrm{e}-\mathrm{g}}$ Means within a column for species that do not have a common superscript $\operatorname{differ}(\mathrm{p}<0.05)$.

addition of $C$. utilis (quadratic, $\mathrm{p}<0.01$ ), $S$. cerevisiae (quadratic, $\mathrm{p}<0.05$ ), and $C$. tropicalis (linear, $\mathrm{p}<0.01$ ). Addition of $C$. utilis at the dose of $0.25 \times 10^{7} \mathrm{cfu}$ decreased $\mathrm{CH}_{4}$ production by $18 \%$ compared with the control. There were interactive effects of species and dose on $\mathrm{pH}(\mathrm{p}<0.05)$, $\mathrm{NH}_{3}-\mathrm{N}(\mathrm{p}<0.01)$ and $\mathrm{CH}_{4}$ production/g IVDMD $(\mathrm{p}<0.01)$.

\section{Volatile fatty acid}

The yeast species influenced $(p<0.01)$ the concentrations of isobutyrate, butyrate, isovalerate, and ratio of acetate to propionate (A:P) in incubation fluids when maize stover was used as substrate (Table 5). For the addition of $S$. cerevisiae, the concentration of isobutyrate was $10 \%$ and $16 \%$ lower, while the concentration of butyrate was $20 \%$ and $12 \%$ higher, when compared to those of $C$. utilis and C. tropicalis treatments respectively. The maximum concentration of isovalerate and A:P were observed in $C$. tropicalis treatment, which were respectively $20 \%$ and $37 \%$, and $9 \%$ and $6 \%$ greater than those of $C$. utilis and $S$. cerevisiae treatments. The addition of $C$. utilis linearly decreased $(p<0.01) \quad A: P$, and it obtained the numerical greatest concentrations of acetate, propionate, isovalerate, and total volatile fatty acids (TVFA) at the dose of $0.50 \times 10^{7} \mathrm{cfu}$, which were respectively $25 \%, 26 \%, 18 \%$, and $27 \%$ greater than the control. The $S$. cerevisiae addition increased the propionate concentration (linear, $p<0.05$ ), but decreased the concentrations of isobutyrate (quadratic, $\mathrm{p}<0.05$ ), isovalerate (quadratic, $\mathrm{p}<0.05$ ), valerate (linear, $\mathrm{p}<0.05$ ), and $\mathrm{A}: \mathrm{P}$ (linear, $\mathrm{p}<0.05$ ). Additionally, the $C$. tropicalis addition linearly increased $(\mathrm{p}<0.01)$ the concentration of isovalerate, reaching the maximum which was $36 \%$ greater than that of the control at the dose of $0.75 \times 10^{7} \mathrm{cfu}$. The interactive effects of species and dose on the concentrations of acetate $(p<0.05)$, butyrate $(p<0.05)$, isovalerate $(p<0.01)$, TVFA $(p<0.05)$, and A:P $(p<0.05)$ were noted respectively.

Regarding to rice straw, the concentrations of isobutyrate, isovalerate, and valerate of incubation fluids were affected $(\mathrm{p}<0.01)$ by yeast species (Table 6$)$. For the $S$. cerevisiae addition, the isobutyrate concentration was respectively $15 \%$ and $18 \%$ less than the addition of $C$. utilis and $C$. tropicalis, while the isovalerate concentration in the C. tropicalis treatment was $19 \%$ and $39 \%$ higher compared to $C$. utilisand $S$. cerevisiae. In addition, the valerate 
Table 4. Effects of different yeast species addition on $\mathrm{pH}, \mathrm{NH}_{3}-\mathrm{N}$ concentration and $\mathrm{CH}_{4}$ production of maize stover and rice straw in vitro

\begin{tabular}{|c|c|c|c|c|c|c|c|c|c|c|c|}
\hline & \multirow[b]{2}{*}{ Item } & \multirow[b]{2}{*}{ Species } & \multicolumn{5}{|c|}{ Dose $\left(\times 10^{7}\right.$ colony-forming unit $)$} & \multirow[b]{2}{*}{ SEM $^{2}$} & \multicolumn{3}{|c|}{ Significance $(>\mathrm{p})^{3}$} \\
\hline & & & Mean $^{1}$ & 0 & 0.25 & 0.50 & 0.75 & & Species & Dose & $\begin{array}{c}\text { Species } \\
\times \text { dose }\end{array}$ \\
\hline \multirow{12}{*}{$\begin{array}{l}\text { Maize } \\
\text { stover }\end{array}$} & \multirow[t]{4}{*}{$\overline{\mathrm{pH}}$} & Candida utilis & 6.46 & $6.50^{\mathrm{ab}}$ & $6.51^{\mathrm{a}}$ & $6.43^{\mathrm{ab}}$ & $6.41^{\mathrm{b}}$ & \multirow[t]{4}{*}{0.033} & NS & $\mathrm{L}(<0.05)$ & \multirow[t]{4}{*}{ NS } \\
\hline & & Saccharomyces cerevisiae & 6.47 & 6.50 & 6.49 & 6.46 & 6.45 & & & NS & \\
\hline & & Candida tropicalis & 6.44 & $6.50^{\mathrm{a}}$ & $6.44^{\mathrm{ab}}$ & $6.41^{\mathrm{ab}}$ & $6.40^{\mathrm{b}}$ & & & $\mathrm{L}(<0.05)$ & \\
\hline & & $\mathrm{SEM}^{4}$ & 0.017 & & & & & & & & \\
\hline & \multirow[t]{4}{*}{$\mathrm{NH}_{3}-\mathrm{N}(\mathrm{mg} / \mathrm{dL})$} & Candida utilis & $7.57^{\mathrm{e}}$ & 7.30 & 7.92 & 7.41 & 7.65 & \multirow[t]{4}{*}{0.269} & $<0.01$ & NS & \multirow[t]{4}{*}{$<0.05$} \\
\hline & & Saccharomyces cerevisiae & $7.14^{\mathrm{f}}$ & $7.30^{\mathrm{ab}}$ & $6.68^{\mathrm{b}}$ & $7.10^{\mathrm{ab}}$ & $7.50^{\mathrm{a}}$ & & & $\mathrm{Q}(<0.05)$ & \\
\hline & & Candida tropicalis & $7.77^{\mathrm{e}}$ & $7.30^{\mathrm{b}}$ & $7.25^{\mathrm{b}}$ & $7.70^{\mathrm{b}}$ & $8.83^{\mathrm{a}}$ & & & $\mathrm{L}(<0.01)$ & \\
\hline & & SEM & 0.135 & & & & & & & & \\
\hline & \multirow{4}{*}{$\begin{array}{l}\mathrm{CH}_{4}(\mathrm{mmol} / \mathrm{g}) \\
\text { IVDMD }\end{array}$} & Candida utilis & $0.44^{\mathrm{f}}$ & 0.43 & 0.38 & 0.49 & 0.46 & \multirow[t]{4}{*}{0.024} & $<0.01$ & NS & \multirow[t]{4}{*}{ NS } \\
\hline & & Saccharomyces cerevisiae & $0.50^{\mathrm{e}}$ & $0.43^{\mathrm{c}}$ & $0.53^{\mathrm{ab}}$ & $0.57^{\mathrm{a}}$ & $0.48^{\mathrm{bc}}$ & & & $\mathrm{Q}(<0.01)$ & \\
\hline & & Candida tropicalis & $0.49^{\mathrm{e}}$ & $0.43^{\mathrm{b}}$ & $0.49^{\mathrm{ab}}$ & $0.54^{\mathrm{a}}$ & $0.52^{\mathrm{a}}$ & & & $\mathrm{L}(<0.01)$ & \\
\hline & & SEM & 0.013 & & & & & & & & \\
\hline \multirow{12}{*}{$\begin{array}{l}\text { Rice } \\
\text { straw }\end{array}$} & \multirow[t]{4}{*}{$\mathrm{pH}$} & Candida utilis & 6.49 & $6.57^{\mathrm{a}}$ & $6.51^{\mathrm{b}}$ & $6.46^{\mathrm{bc}}$ & $6.42^{\mathrm{c}}$ & \multirow[t]{4}{*}{0.019} & NS & $\mathrm{L}(<0.01)$ & \multirow[t]{4}{*}{$<0.05$} \\
\hline & & Saccharomyces cerevisiae & 6.50 & $6.57^{\mathrm{a}}$ & $6.49^{\mathrm{b}}$ & $6.48^{\mathrm{b}}$ & $6.46^{\mathrm{b}}$ & & & $\mathrm{Q}(<0.05)$ & \\
\hline & & Candida tropicalis & 6.50 & $6.57^{\mathrm{a}}$ & $6.48^{\mathrm{bc}}$ & $6.44^{\mathrm{c}}$ & $6.52^{\mathrm{ab}}$ & & & $\mathrm{Q}(<0.01)$ & \\
\hline & & SEM & 0.010 & & & & & & & & \\
\hline & \multirow[t]{4}{*}{$\mathrm{NH}_{3}-\mathrm{N}(\mathrm{mg} / \mathrm{dL})$} & Candida utilis & $6.30^{\mathrm{f}}$ & 6.33 & 5.91 & 6.64 & 6.30 & \multirow[t]{4}{*}{0.276} & $<0.01$ & NS & \multirow[t]{4}{*}{$<0.01$} \\
\hline & & Saccharomyces cerevisiae & $5.87^{\mathrm{g}}$ & $6.33^{\mathrm{a}}$ & $5.73^{\mathrm{ab}}$ & $5.24^{\mathrm{b}}$ & $6.16^{\mathrm{a}}$ & & & $\mathrm{Q}(<0.01)$ & \\
\hline & & Candida tropicalis & $7.14^{\mathrm{e}}$ & $6.33^{\mathrm{b}}$ & $7.14^{\mathrm{a}}$ & $7.58^{\mathrm{a}}$ & $7.51^{\mathrm{a}}$ & & & $\mathrm{L}(<0.01)$ & \\
\hline & & SEM & 0.138 & & & & & & & & \\
\hline & \multirow{4}{*}{$\begin{array}{l}\mathrm{CH}_{4}(\mathrm{mmol} / \mathrm{g}) \\
\text { IVDMD }\end{array}$} & Candida utilis & $0.35^{\mathrm{f}}$ & $0.34^{\mathrm{b}}$ & $0.28^{\mathrm{c}}$ & $0.36^{\mathrm{b}}$ & $0.41^{\mathrm{a}}$ & \multirow[t]{4}{*}{0.018} & $<0.01$ & $\mathrm{Q}(<0.01)$ & \multirow[t]{4}{*}{$<0.01$} \\
\hline & & Saccharomyces cerevisiae & $0.38^{\mathrm{e}}$ & $0.34^{\mathrm{b}}$ & $0.40^{\mathrm{a}}$ & $0.40^{\mathrm{a}}$ & $0.39^{\mathrm{ab}}$ & & & $\mathrm{Q}(<0.05)$ & \\
\hline & & Candida tropicalis & $0.39^{\mathrm{e}}$ & $0.34^{\mathrm{b}}$ & $0.40^{\mathrm{a}}$ & $0.41^{\mathrm{a}}$ & $0.42^{\mathrm{a}}$ & & & $\mathrm{L}(<0.01)$ & \\
\hline & & SEM & 0.009 & & & & & & & & \\
\hline
\end{tabular}

SEM, standard error of the mean; NS, not significant.

${ }^{1}$ Mean for individual species across doses including the dose of 0 .

${ }^{2}$ SEM for strain $\times$ dose.

${ }^{3} \mathrm{NS}(\mathrm{p}>0.05) ; \mathrm{L}=$ linear effect of dose, $\mathrm{Q}=$ quadratic effect of dose.

${ }^{4} \mathrm{SEM}$ for pooled mean of species including the dose of 0 .

${ }^{\mathrm{a}-\mathrm{c}}$ Means within a row for doses that do not have a common superscript differ $(\mathrm{p}<0.05)$.

${ }^{\mathrm{e}-\mathrm{g}}$ Means within a column for species that do not have a common superscript differ $(\mathrm{p}<0.05)$.

concentration in the $C$. utilis treatment was respectively $41 \%$ isovelerate $(\mathrm{p}<0.01)$ were also observed.

and $23 \%$ greater than that in the $S$. cerevisiae and $C$. tropicalis treatments. The $C$. utilis addition linearly increased $(\mathrm{p}<0.05)$ the concentration of isobutyrate and reached the peak which was $16 \%$ greater than that of the control, while the concentrations of isovalerate and valerate were both quadratically reduced $(\mathrm{p}<0.05)$ by adding $S$. cerevisiae. The $C$. tropicalis addition linearly increased the concentrations of isobutyrate $(\mathrm{p}<0.05)$ and isovalerate $(p<0.01)$ reaching the maximum at the dose of $0.75 \times 10^{7} \mathrm{cfu}$, but quadratically decreased $(p<0.05)$ the valerate concentration. Besides, the A:P reached the numerical minimum with the addition of $C$. utilis and $S$. cerevisiae both at the doses of $0.25 \times 10^{7} \mathrm{cfu}$, while it was obtained at the dose of $0.50 \times 10^{7} \mathrm{cfu}$ in the C. tropicalis treatment, which were respectively $14 \%, 9 \%$, and $11 \%$ less than that of the control. The interactive actions of species and dose on the concentrations of isobutyrate $(\mathrm{p}<0.05)$ and

\section{DISCUSSION}

As a matter of fact, the effectiveness of yeast addition on in vitro GP parameters is somehow inconsistent in some previous studies. Mutsvangwa et al. (1992) reported that in vitro GP of a barley diet for beef cattle supplemented with yeast culture (Yea-Sacc1026) was on average less than that in the control, while Tang et al. (2008) found that supplementation of yeast culture (Original XP; Diamond V Mills Inc., Cedar Rapids, IA, USA) increased the cumulative GP, theoretical maximum of GP and the rate of GP of low quality roughages. This disparity might be caused by the difference in the yeast species used in their studies, fermentation substrate and experimental conditions. In the present study, adding $C$. utilis at all the designated doses decreased in vitro GP compared to the control, which 
Table 5. Effects of different yeast species addition on volatile fatty acids concentration of in vitro incubation fluids for maize stover

\begin{tabular}{|c|c|c|c|c|c|c|c|c|c|c|}
\hline \multirow{2}{*}{ Item $^{1}$} & \multirow{2}{*}{ Species } & \multicolumn{5}{|c|}{ Dose $\left(\times 10^{7}\right.$ colony-forming unit) } & \multirow{2}{*}{$\mathrm{SEM}^{3}$} & \multicolumn{3}{|c|}{ Significance $(>p)^{4}$} \\
\hline & & Mean $^{2}$ & 0 & 0.25 & 0.50 & 0.75 & & Species & Dose & Species $\times$ dose \\
\hline \multirow[t]{4}{*}{ Acetate $(\mathrm{mM})$} & Candida utilis & 18.08 & 17.97 & 16.56 & 22.39 & 15.40 & 1.260 & NS & NS & $<0.05$ \\
\hline & Saccharomyces cerevisiae & 18.55 & 17.97 & 17.36 & 18.91 & 19.96 & & & NS & \\
\hline & Candida tropicalis & 18.79 & 17.97 & 19.43 & 18.03 & 19.75 & & & NS & \\
\hline & SEM $^{5}$ & 0.630 & & & & & & & & \\
\hline \multirow[t]{4}{*}{ Propionate (mM) } & Candida utilis & 8.51 & 8.07 & 7.90 & 10.20 & 7.86 & 0.561 & NS & NS & NS \\
\hline & Saccharomyces cerevisiae & 8.79 & $8.07^{b}$ & $8.44^{\mathrm{ab}}$ & $8.95^{\mathrm{ab}}$ & $9.72^{\mathrm{a}}$ & & & $\mathrm{L}(<0.05)$ & \\
\hline & Candida tropicalis & 8.38 & 8.07 & 8.48 & 8.20 & 8.77 & & & NS & \\
\hline & SEM & 0.280 & & & & & & & & \\
\hline \multirow[t]{4}{*}{ Isobutyrate $(\mathrm{mM})$} & Candida utilis & $0.30^{\mathrm{e}}$ & 0.31 & 0.26 & 0.33 & 0.29 & 0.020 & $<0.01$ & NS & NS \\
\hline & Saccharomyces cerevisiae & $0.27^{\mathrm{f}}$ & $0.31^{\mathrm{a}}$ & $0.24^{\mathrm{b}}$ & $0.25^{\mathrm{b}}$ & $0.27^{\mathrm{ab}}$ & & & $\mathrm{Q}(<0.05)$ & \\
\hline & Candida tropicalis & $0.32^{\mathrm{e}}$ & 0.31 & 0.32 & 0.32 & 0.34 & & & NS & \\
\hline & SEM & 0.010 & & & & & & & & \\
\hline \multirow[t]{4}{*}{ Butyrate (mM) } & Candida utilis & $1.73^{\mathrm{f}}$ & 1.83 & 1.52 & 2.18 & 1.39 & 0.150 & $<0.01$ & NS & $<0.05$ \\
\hline & Saccharomyces cerevisiae & $2.08^{\mathrm{e}}$ & 1.83 & 2.14 & 2.18 & 2.18 & & & NS & \\
\hline & Candida tropicalis & $1.85^{\mathrm{f}}$ & 1.83 & 1.93 & 1.73 & 1.91 & & & NS & \\
\hline & SEM & 0.075 & & & & & & & & \\
\hline \multirow[t]{4}{*}{ Isovalerate $(\mathrm{mM})$} & Candida utilis & $0.40^{\mathrm{f}}$ & 0.39 & 0.35 & 0.46 & 0.40 & 0.022 & $<0.01$ & NS & $<0.01$ \\
\hline & Saccharomyces cerevisiae & $0.35^{\mathrm{g}}$ & $0.39^{\mathrm{a}}$ & $0.32^{\mathrm{b}}$ & $0.33^{\mathrm{ab}}$ & $0.35^{\mathrm{ab}}$ & & & $\mathrm{Q}(<0.05)$ & \\
\hline & Candida tropicalis & $0.48^{\mathrm{e}}$ & $0.39^{b}$ & $0.50^{\mathrm{a}}$ & $0.50^{\mathrm{a}}$ & $0.53^{\mathrm{a}}$ & & & $\mathrm{L}(<0.01)$ & \\
\hline & SEM & 0.011 & & & & & & & & \\
\hline \multirow[t]{4}{*}{ Valerate (mM) } & Candida utilis & 0.46 & 0.56 & 0.36 & 0.48 & 0.46 & 0.069 & NS & NS & NS \\
\hline & Saccharomyces cerevisiae & 0.37 & $0.56^{\mathrm{a}}$ & $0.30^{\mathrm{b}}$ & $0.30^{\mathrm{b}}$ & $0.32^{\mathrm{b}}$ & & & $\mathrm{L}(<0.05)$ & \\
\hline & Candida tropicalis & 0.41 & 0.56 & 0.34 & 0.35 & 0.38 & & & NS & \\
\hline & SEM & 0.034 & & & & & & & & \\
\hline \multirow[t]{4}{*}{ A:P } & Candida utilis & $2.03^{\mathrm{f}}$ & $2.21^{\mathrm{a}}$ & $2.04^{\mathrm{b}}$ & $1.95^{\mathrm{bc}}$ & $1.90^{\mathrm{c}}$ & 0.048 & $<0.01$ & $\mathrm{~L}(<0.01)$ & $<0.05$ \\
\hline & Saccharomyces cerevisiae & $2.09^{\mathrm{f}}$ & $2.21^{\mathrm{a}}$ & $2.05^{\mathrm{b}}$ & $2.09^{\mathrm{ab}}$ & $2.02^{\mathrm{b}}$ & & & $\mathrm{L}(<0.05)$ & \\
\hline & Candida tropicalis & $2.21^{\mathrm{e}}$ & 2.21 & 2.27 & 2.14 & 2.23 & & & NS & \\
\hline & SEM & 0.024 & & & & & & & & \\
\hline \multirow[t]{4}{*}{ TVFA (mM) } & Candida utilis & 29.70 & 29.11 & 26.95 & 36.87 & 25.84 & 1.903 & NS & NS & $<0.05$ \\
\hline & Saccharomyces cerevisiae & 30.40 & 29.11 & 28.78 & 30.92 & 32.79 & & & NS & \\
\hline & Candida tropicalis & 30.22 & 29.11 & 31.00 & 29.12 & 31.67 & & & NS & \\
\hline & SEM & 0.962 & & & & & & & & \\
\hline
\end{tabular}

SEM, standard error of the mean; NS, not significant.

${ }^{1} \mathrm{TVFA}=$ total short chain fatty acids, $\mathrm{A}: \mathrm{P}=$ ratio of acetate to propionate.

${ }^{2}$ Mean for individual species across doses including the dose of 0 .

${ }^{3}$ SEM for strain $\times$ dose.

${ }^{4} \mathrm{NS}(\mathrm{p}>0.05), \mathrm{L}=$ linear effect of dose, $\mathrm{Q}=$ quadratic effect of dose.

${ }^{5} \mathrm{SEM}$ for pooled mean of species including the dose of 0 .

${ }^{a-c}$ Means within a row for doses that do not have a common superscript differ $(p<0.05)$

${ }^{\mathrm{e}-\mathrm{g}}$ Means within a column for species that do not have a common superscript $\operatorname{differ}(\mathrm{p}<0.05)$.

was in agreement with the results obtained by Mutsvangwa et al. (1992). Meanwhile, maize stover or rice straw supplemented with $S$. cerevisiae and $C$. tropicalis achieved greater GP than that supplemented with $C$. utilis, suggesting that the selection of yeast species should be taken into consideration when live yeast was applied to improve in vitro fermentation efficiency of forages. Indexes of $F R D_{0}$ and $T_{0.5}$ usually reflect the rate of degradation at early incubation stages of ' $<12 \mathrm{~h}$ ' and the incubation time of reaching half of the maximum GP, respectively. In general, the $F R D_{0}$ is inversely proportional to $t_{0.5}$. The addition of $C$. utilis and $C$. tropicalis decreased $t_{0.5}$ but increased $F R D_{0}$ of rice straw fermentation, indicating that the rate of degradation would be faster at the early stage of in vitro fermentation. Moreover, the two reverse responses of $t_{0.5}$ in $S$. cerevisiae and C. tropicalis treatments for maize stover indicated that the influence on the rate of degradation would be dependent on the yeast species, but this hypothesis required further research to be conducted. The alteration in the rate of degradation in response to yeast culture addition has also been verified in some previous studies. For instance, Newbold et al. (1995) suggested that $S$. cerevisiae 
culture stimulated the rate rather than the extent of degradation by ruminal micro-organisms. Sullivan and Martin (1999) found S. cerevisiae culture filtrate stimulated the initial rate of cellulose degradation. In addition, the decrease of $V f$ and $k$ caused by $C$. utilis addition in comparison with control suggested that this yeast species might not be suitable for dietary supplement.

It was noted in the study that the increase or decrease of IVDMD and IVNDFD of maize stover and rice straw was depended upon different yeast species, as C. utilis reduced both IVDMD and IVNDFD while $C$. tropicalis improved IVDMD and IVNDFD, and $S$. cerevisiae did not affect IVDMD and IVNDFD being dose-dependent. Furthermore, we found that the two higher supplemental doses of C. utilis did not always ensure the higher IVDMD and IVNDFD compared to the dose of $0.25 \times 10^{7} \mathrm{cfu} / 500 \mathrm{mg}$, which was similar to the findings of Tang et al. (2008). In the study of Tang et al. (2008), the greatest values of IVDMD occurred for maize stover, maize stover silage, and wheat straw when yeast culture was supplemented at the level of $5.0 \mathrm{~g} / \mathrm{kg}$ rather than the higher level of $7.5 \mathrm{~g} / \mathrm{kg}$. However, this phenomenon lacked sufficient explanation and needs to be fully studied in further research. Considering both IVDMD and IVNDFD could be more closely related to in vivo conditions, it is suggested that $C$. tropicalis should be more appropriate for supplements at the dose of $0.25 \times 10^{7} \mathrm{cfu} / 500$ mg substrates.

As $\mathrm{pH}$ value is a main index reflecting the internal homeostasis of rumen environment, therefore maintaining a relatively stable ruminal $\mathrm{pH}$ is vital to assuring efficient rumen fermentation. Ruminants usually possess highly developed systems to maintain ruminal $\mathrm{pH}$ within a physiological range of about 5.5 to 7.0 (Krause and Oetzel, 2006). In this study, although adding C. utilis, S. cerevisiae, and $C$. tropicalis, respectively lowered $\mathrm{pH}$ value to different extents, whilst $\mathrm{pH}$ value across all treatments ranged from 6.40 to 6.57 , which still kept a suitable condition for fermentation, growth of microorganism, and fiber degradation in the rumen (Stewart et al., 1997). Satter and Slyter (1974) suggested that the lowest $\mathrm{NH}_{3}-\mathrm{N}$ concentration of rumen liquor should not be less than 5 $\mathrm{mg} / \mathrm{dL}$ to maintain the higher growth rate of bacteria. Deficiency of $\mathrm{NH}_{3}-\mathrm{N}$ restricts the microbial protein synthesis, while an overly high $\mathrm{NH}_{3}-\mathrm{N}$ concentration also inhibits the microbial utilization of $\mathrm{NH}_{3}-\mathrm{N}$ (Hristov et al., 2002). Concentration of $\mathrm{NH}_{3}-\mathrm{N}$ across three yeast treatments ranged from 5.24 to $8.83 \mathrm{mg} / \mathrm{dL}$ in this study, indicating that the growth and protein synthesis of microorganisms was not restricted. Fadel Elseed et al. (2007) reported yeast (S. cerevisiae) supplementation resulted in a numerical increase in ammonia-N concentration in rumen fluid of Nubian goat's kids. Similarly, the inclusion of $C$. utilis and $C$. tropicalis could enhance $\mathrm{NH}_{3}-\mathrm{N}$ concentration to different extents with maize stover as fermented substrate, while for rice straw, only C. tropicalis addition elevated $\mathrm{NH}_{3}-\mathrm{N}$ concentration of incubation fluids.

Methanogenesis is an essential metabolic pathway for hydrogen elimination and subsequently for efficient degradation of plant cell wall carbohydrates in the rumen (Wolin et al., 1997). Since yeast, especially $S$. cerevisiae, is the most frequently used direct-fed microbial in ruminant production, its influence on methanogenesis has been investigated in a few studies both in vitro and in vivo, but the results of these studies are inconsistent. In present study, the addition of $S$. cerevisiae and $C$. tropicalis respectively increased $\mathrm{CH}_{4}$ production/g IVDMD of crop straws. The elevation of $\mathrm{CH}_{4}$ production might be due to the increased disappearance of fiber under the in vitro closed anaerobic environment. Qiao and Shan (2006) found that addition of $S$. cerevisiae and Saccharomycopsis fibuligera also increased in vitro methane production, while C. tropicalis addition decreased $\mathrm{CH}_{4}$ production with cornstarch, soybean, and wheat bran plus concentrate $(3: 1)$ mixture as the fermented substrates. It was inferred that the reduced $\mathrm{CH}_{4}$ production might be attributed to the suppressed methanogens in the rumen, while the enhanced $\mathrm{CH}_{4}$ production could be caused by the stimulated methanogens. Nevertheless, the inconsistency in results from different studies necessitates further research on this topic.

A number of trials have been conducted to examine the effects of yeast culture supplements on VFA in the rumen. Dawson et al. (1990) reported that the VFA patterns were not altered by yeast supplement (S. cerevisiae) in either rumen-simulating cultures or in the rumens of steers, while Mutsvangwa et al. (1992) found the addition of yeast culture (Yea-Sacc1026) increased the concentration of acetate and TVFA both in vitro and in vivo. In this study, not only $V f, k$, IVDMD, and IVNDFD, but also the production of VFA was decreased by supplementing C. utilis, which indicated that $C$. utilis might be unsuitable as an additive for enhancing in vitro fermentation of cereal straws. Besides, supplementing $S$. cerevisiae and C. tropicalis elevated $\mathrm{CH}_{4}$ production without significantly increasing VFA concentrations could be regarded as a disadvantage for in vitro fermentation of cereal straws. In addition, it was found that $S$. cerevisiae and C. tropicalis addition increased the propionate concentration, but decreased the concentrations of isovalerate and valeratein vitro with the increasing dose with maize stover and rice straw as fermented substrates. The decline of isovalerate and valerate concentrations suggested that $S$. cerevisiae and $C$. tropicalis addition have potential to stimulate plant cell wall digestion and ammonia utilization by mixed ruminal bacteria, as it was found that cell wall digestion and ammonia utilization were increased by low concentrations of isovalerate and valerate (Gorosito et al., 1985). Additionally, our results showed that the 
addition of these three yeasts decreased or numerically decreased A:P, this was in agreement with the in vitro finding of Martin et al. (1989). In contrast, Mutsvangwa et al. (1992) pointed out that yeast culture addition did not alter A:P in vitro and in vivo, whereas Arambel et al. (1987) reported that $\mathrm{A}: \mathrm{P}$ in the in vitro rumen fermentation supplemented with a yeast culture increased. This variation could be attributed to different species or strains of yeast used in different studies or the distinction between live yeast and yeast culture, and it needs to be investigated via further experiments.

\section{CONCLUSION}

In conclusion, both $S$. cerevisiae and $C$. tropicalis are more desirable than $C$. utilis as yeast culture supplements. Further, $C$. tropicalis is preferred compared to $S$. cerevisiae and its optimal dose should be $0.25 \times 10^{7} \mathrm{cfu} / 500 \mathrm{mg}$ substrates, as $C$. tropicalis enhanced IVDMD and IVNDFD, and digestibility was viewed as the most fundamental parameter reflecting in vitro fermentation of cereal straws. The finding obtained from this study provides the dairy farmers with a practicable reference on the selection of live yeast species as feed additives. However, the verification of effects on these three live yeast additives in vivo, the evaluation of more live yeast additives for improving rumen fermentation, and the explanation of mechanisms of live yeast additives in ruminants all require further research in future.

\section{CONFLICT OF INTEREST}

We certify that there is no conflict of interest with any financial organization regarding the material discussed in the manuscript.

\section{ACKNOWLEDGMENTS}

The authors wish to acknowledge the financial support received from the International Atomic Energy Agency (16315), "Strategic Priority Research Program - Climate Change: Carbon Budget and Relevant Issues" (Grant No. XDA05020700), the National Natural Science Foundation of China (Grant No. 31320103917), the Ministry of Science and Technology of China (Grant NO. 2012BAD12B02, 2012BAD14B17), and the Chinese Academy of Sciences (Grant NO. KZCX2-XB3-04, KFJ-EW-STS-071).

\section{REFERENCES}

AOAC. 1999. Official Methods of Analysis. 16th edn. Association of Official Analytical Chemists, Arlington, VA, USA.

Arambel, M. J., R. D. Wiedmeier, and J. L. Walters. 1987. Influence of donor animal adaptation to added yeast culture and/or Aspergillus oryzae fermentation extract on in vitro rumen fermentation. Nutr. Rep. Int. 35:433-437.

Chaucheyras-Durand, F., N. D. Walker, and A. Bach. 2008. Effects of active dry yeasts on the rumen microbial ecosystem: Past, present and future. Anim. Feed Sci. Technol. 145:5-26.

Dawson, K. A., K. E. Newman, and J. A. Boling. 1990. Effects of microbial supplements containing yeast and lactobacilli on roughage-fed ruminal microbial activities. J. Anim. Sci. 68:3392-3398.

Estefan, G. 1999. Feedyard Performance and Carcass Traits of Cattle as Influenced by Stocker Phase Implant Strategy and Yeast Culture $(S$. cerevisiae $8 \times 109 \mathrm{CFU} / \mathrm{g} ; \mathrm{BIOSAF})$ Supplementation during the Feedyard Phase. Ph.D. Thesis, Texas A\&M University, Amarillo, TX, USA.

FadelElseed, A. M. and R. M. Abusamra. 2007. Effects of supplemental yeast (Saccharomyces cerevisiae) culture on NDF digestibility and rumen fermentation of forage sorghum hay in Nubian goat's kids. Res. J. Agric. Biol. Sci. 3:133-137.

Gorosito, A. R., J. B. Russell, and P. J. van Soest. 1985. Effect of carbon- 4 and carbon-5 volatile fatty-acids on digestion of plant-cell wall in vitro. J. Dairy Sci. 68:840-847.

Holtshausen, L. and K. A. Beauchemin. 2010. Supplementing barley-based dairy cow diets with Saccharomyces cerevisiae. Prof. Anim. Sci. 26:285-289.

Hristov, A. N., J. K. Ropp, and C. W. Hunt. 2002. Effect of barley and its amylopectin content on ruminal fermentation and bacterial utilization of ammonia-N in vitro. Anim. Feed Sci. Technol. 99:25-36.

Jouany, J. P. 2001. A new look at yeast cultures as probiotics for ruminants. Feed Mix. 9:17-19.

Krause, K. M. and G. R. Oetzel. 2006. Understanding and preventing subacute ruminal acidosis in dairy herds: A review. Anim. Feed Sci. Technol. 126:215-236.

Martin, S. A., D. J. Nisbet, and R. G. Dean. 1989. Influence of a commercial yeast supplement on the in vitro ruminal fermentation. Nutr. Rep. Int. 40:395-403.

Moallem, U., H. Lehrer, L. Livshitz, M. Zachut, and S. Yakoby. 2009. The effects of live yeast supplementation to dairy cows during the hot season on production, feed efficiency, and digestibility. J. Dairy Sci. 92:343-351.

Mutsvangwa, T., I. E. Edwards, J. H. Topps, and G. F. Paterson. 1992. The effect of dietary inclusion of yeast culture (Yea-Sacc) on patterns of rumen fermentation, food-intake and growth of intensively fed bulls. Anim. Prod. 55:35-40.

Newbold, C. J., R. J. Wallace, X. B. Chen, and F. M. Mcintosh. 1995. Different strains of Saccharomyces cerevisiae differ in their effects on ruminal bacterial numbers in vitro and in sheep. J. Anim. Sci. 73:1811-1818.

Qiao, G. H. and A. S. Shan. 2006. The effect of different direct-fed microbial culture on methane production in vitro and production performance in dairy cattle. China Anim. Husb. Vet. Med. 33:11-14.

SAS Institute Inc. 2001. The SAS system for Microsoft Windows: release 8.2. SAS Institute Inc., Cary, NC, USA.

Satter, L. D. and L. L. Slyter. 1974. Effect of ammonia concentration of rumen microbial protein production in vitro. Br. J. Nutr. 32:199-208.

Stewart, C. S., H. J. Flint, and M. P. Bryant. 1997. The rumen bacteria. In: The Rumen Microbial Ecosystem II (Eds. P. N. 
Hobson and C. S. Stewart). Chapman and Hall, London, UK. pp. 10-72.

Sullivan, H. M. and S. A. Martin. 1999. Effects of a Saccharomyces cerevisiae culture on in vitro mixed ruminal microorganism fermentation. J. Dairy Sci. 82:2011-2016.

Tang, S., Z. Tan, C. Zhou, H. Jiang, Y. Jiang, and L. Sheng. 2006. A comparison of in vitro fermentation characteristics of different botanical fractions of mature maize stover. J. Anim. Feed Sci. 15:505-515.

Tang, S. X., G. O. Tayo, Z. L. Tan, Z. H. Sun, L. X. Shen, C. S. Zhou, W. J. Xiao, G. P. Ren, X. F. Han, and S. B. Shen. 2008. Effects of yeast culture and fibrolytic enzyme supplementation on in vitro fermentation characteristics of low-quality cereal straws. J. Anim. Sci. 86:1164-1172.
Van Soest, P. V., J. B. Robertson, and B. A. Lewis. 1991. Methods for dietary fiber, neutral detergent fiber, and nonstarch polysaccharides in relation to animal nutrition. J. Dairy Sci. 74:3583-3597.

Wang, M., X. Z. Sun, S. X. Tang, Z. L. Tan, and D. Pacheco. 2013. Deriving fractional rate of degradation of logistic-exponential (LE) model to evaluate early in vitro fermentation. Animal 7:920-929.

Wang, M., S. X. Tang, and Z. L. Tan. 2011. Modeling in vitro gas production kinetics: Derivation of Logistic-Exponential (LE) equations and comparison of models. Anim. Feed Sci. Technol. 165:137-150.

Wolin, M. J., T. L. Miller, and C. S. Stewart. 1997. Microbe: Microbe interactions. In: The Rumen Microbial Ecosystem II (Eds. P. N. Hobson and C. S. Stewart). Chapman and Hall, London, UK. pp. 467-491. 